\title{
PRAKTIK YOGA ASANA DALAM MENORMALKAN TEKANAN DARAH DI KELOMPOK LANSIA BALI MOVEMENT BANJAR BATANBUAH DAUH YEH CANI BADUNG
}

\author{
Oleh:
}

\author{
I Wayan Artana, Ni Putu Dita Wulandari, dan Claudia Wuri Prihandini \\ wayan.artana473@gmail.com
}

Prodi Keperawatan STIKES Bina Usada Bali

Proses Review 02-28 September, Dinyatakan Lolos 02 Oktober

\begin{abstract}
Decreased function of elderly cardiovascular organs results in hypertension namely systolic blood pressure (TDS) $\geq 140 \mathrm{mmHg}$ and diastolic blood pressure (TDD) $\geq 90 \mathrm{mmHg}$. Hypertension is treated with medications from doctors and traditional yoga asanas. The study aims to determine the effect of yoga asanas on blood pressure in the elderly group of the Bali Movement Banjar Batanbuah, Abs Dauh Yeh Cani, Abiansemal, Badung. Using a pretest-posttest experimental mix study without control and phenomenology. The sample consisted of 40 people and several samples were used as informants. Objectively the average TDS and TDD before yoga asanas are hypertension, $141.00 \mathrm{mmHg}$ and $90.00 \mathrm{mmHg}$, while after yoga the asanas TDS and TDD are normal, $120.75 \mathrm{mmHg}$ and $80.75 \mathrm{mmHg}$. The Wilcoxon Test analysis at $\alpha=0.05$ found $p$ value 0.001, which means that there is an influence of yoga asanas on hypertension in the elderly, and subjectively the informant feels the benefits of yoga asanas to lower their blood pressure. Hypertensive elderly can use yoga asanas as a treatment for hypertension together with medications from doctors.
\end{abstract}

Keywords: elderly, cardiovascular, hypertension, medicine, yoga asanas.

\begin{abstract}
Abstrak
Penurunan fungsi organ kardiovaskuler lansia mengakibatkan hipertensi yaitu tekanan darah sistolik (TDS) $\geq 140 \mathrm{mmHg}$ dan tekanan darah diastolik (TDD) $\geq 90 \mathrm{mmHg}$. Hipertensi diobati dengan obat-obat dari dokter dan tradisional yoga asana. Penelitian bertujuan mengetahui pengaruh yoga asana terhadap tekanan darah di kelompok lansia Bali Movement Banjar Batanbuah, Abs Dauh Yeh Cani, Abiansemal, Badung. Menggunakan mix study eksperimental pretest-posttest tanpa kontrol dan fenomenologi. Sampel berjumlah 40 orang dan beberapa sampel digunakan sebagai informan. Secara obyektif rata-rata TDS dan TDD sebelum yoga asana adalah hipertensi
\end{abstract}


yaitu 141,00 mmHg dan 90,00 $\mathrm{mmHg}$, sedangkan setelah yoga asana TDS dan TDD menjadi normal yaitu $120,75 \mathrm{mmHg}$ dan $80,75 \mathrm{mmHg}$. Analisa Wilcoxon Test pada $\alpha=0,05$ ditemukan $p$ value 0,001, yang artinya ada pengaruh yoga asana terhadap tekanan darah lansia hipertensi, dan secara subyektif informan merasakan manfaat yoga asana untuk menurunkan tekanan darahnya. Lansia yang hipertensi dapat menggunakan yoga asana sebagai pengobatan hipertensi bersama-sama obat dari dokter.

Kata kunci: lansia, kardiovaskuler, hipertensi, obat, yoga asana.

\section{PENDAHULUAN}

Lanjut usia (Lansia) seperti dijelaskan pada Undang-Undang RI Nomor 13 tahun 1998 merupakan seseorang yang telah mencapai usia 60 tahun ke atas. Lansia mengalami penurunan fungsi organ yang berkaitan dengan jantung dan pembuluh darah (kardiovaskuler) (Sylvia and Lorraine, 2008). Ketidakefektipan fungsi sistem tersebut, menjadikan tubuh berusaha secara maksimal untuk memenuhi kebutuhannya akan darah bagi organ-organ lainnya, karena lewat darahlah zat makanan dan oksigen diedarkan. Usaha yang dilakukannya dengan cara meningkatkan tekanan dari jantung dan mempersempit saluran-saluran darah (Pranawa, Artaria Tjempakasari, 2015; Dee Unglaub Silverthon,2013). Dengan demikian, tekanan darah akan meningkat (hipertensi).

Tekanan darah dikatakan normal bila tekanan jantung untuk memompa darah ke seluruh tubuh (tekanan darah sistolik/TDS) besarnya $120 \mathrm{mmHg}$ diukur dengan alat tensimeter digital, begitu pula tekanan darah saat darah masuk menuju jantung (tekanan darah diastolik/TDD) berkisar $80 \mathrm{mmHg}$. Di antara tekanan darah normal dan tekanan darah tinggi ada yang disebut tekanan darah prehipertensi. Seseorang dikatakan menderita hipertensi, bila TDSnya $\geq 140 \mathrm{mmHg}$ dan TDDnya $\geq 90 \mathrm{mmHg}$ (PERHI,2019): (PERKI,2016).

Kejadian hipertensi di Indonesia terus mengalami peningkatan dari tahun ke tahun. Dari catatan riset kesehatan dasar (Riskesdas) 2013 diketahui bahwa penduduk Indonesia yang berumur $\geq 18$ tahun dan menderita hipertensi ada sebanyak 25,8\%. Ini berarti dari 100 orang penduduk yang berumur $\geq 18$ tahun, ada 25-26 orang yang mempunyai penyakit hipertensi (Kemenkes RI,2014). Peningkatan kejadian hipertensi terulang di 2018, dengan dicatatnya hasil Riskesdas untuk hipertensi sebesar 34,1\% (Kemenkes RI, 2018).

Bali juga mengalami hal yang sama dalam peningkatan hipertensi. Pada 2013 kejadiannya kurang dari 13,71\% dan tahun 2018 sudah mencapai 13,7\%. Akan tetapi, kejadian hipertensi di Bali lebih rendah dibandingkan dengan kejadiannya di Indonesai. Studi pendahuluan yang dilakukan 20 Juni 2019 di kelompok lansia Bali Movement Banjar Batanbuah, Abs Dauh Yeh Cani, Abiansemal, Badung, ditemukan jumlah lansia sebanyak 70 orang terdiri dari 25 laki-laki $(35,7 \%)$ dan 45 perempuan $(64,3 \%)$. Jumlah yang mengalami hipertensi ada $40(57,1 \%)$ orang dan yang tidak mengalami hiperteni 30 (42,8\%) orang.

Pada perkumpulan tersebut lansia rutin melakukan senam yoga setiap hari Selasa dan Minggu. Suatu aktifitas olahraga akan ada manfaatnya bagi pelatihan tubuh bila dilakukan tiga sampai lima kali dalam seminggu (Nala, 2011). Pada penelitian ini aktifitas yoga ditambahkan lagi sekali di hari kamis, sehingga yoga asana pada kelompok lansia dilakukan tiga kali seminggu yang hari Selasa, Kamis, dan Minggu.

Yoga merupakan warisan budaya yang adiluhung sudah menjadi gaya hidup masyarakat modern sekarang ini (Nuraeni, Heny Gustini dan Alfan, Muhammad. 2013; Hemamalini, 2017). Di Bali gaya hidup ini sangat digemari oleh penduduk terutama bagi yang ingin membentuk tubuhnya menjadi langsing. Dengan yoga asana tubuh fisik akan digerakkan, yang dapat juga dikatakan sebagai olahraga (Suryani, LK.2010; Widodo GG, Purwanigsih P. 2013).

Maksudnya dengan yoga asana sistem 
kardiovaskuler terutama pembuluh darah akan menjadi elastis diakibatkan terpakainya lemak tubuh. Selain itu akan meningkatkan kemampuan jantung mengalirkan darah ke seluruh tubuh, tetapi denyutnya akan teratur. Yoga asana pada tatanan psikologis tubuh dapat merelaksasikan pikiran dan emosi, karena yoga asana merupakan memusatkan pikiran kepada Sang Sumber dengan melakukan gerakangerakan tubuh (Artadi, I Ketut. 2011; Artana, 2017; Muliadi, 2017). Suatu situasi yang demikian, diharapkan tekanan darah akan dapat menurun (Hill, P.C., Hood, R.W., \& Spilka, B. 2009; Dee Unglaub Silverthorn. 2013).

Artikel yang ditulis ini akan membahas tiga permasalahan utama yaitu bagaimana umur kronologis dan keturunan memengaruhi kejadian hipertensi. Bagaimanakah perbandingan tekanan darah lansia sebelum dan setelah melakukan yoga asana. Mampukah yoga asana menormalkan tekanan darah lansia yang mengalami hipertensi di kelompok lansia Bali Movement Banjar Batanbuah, Abs Dauh Yeh Cani, Abiansemal, Badung.

\section{METODE PENELITIAN}

Penelitian ini menggunakan pendekatan mix method yaitu metode kuantitatif eksperimental pre-post test design dan kualitatif fenomenologi. Sumber data berasal dari hasil pengukuran, informan, proses, dan dokumen. Teknik pengumpulan data yang digunakan yakni pengukuran, wawancara terstruktur, observasi, dan analisis dokumen (Notoatmodjo.2010; Emzir. 2016; Martono, Nanang. 2015). Pengamatan atau observasi sangat penting dilakukan untuk melihat kesungguhan lansia melakukan yoga asana dan melakukan pengukuran tekanan darah.

Wawancara dilakukan untuk mengetahui bagaimana penilaian lansia tentang dirinya sebelum dan setelah melakukan yoga asana. Analisis dokumen dilakukan sebagai cara pengumpulan data tambahan dan triangulasi data. Penelusuran pustaka juga penting khususnya yang berhubungan dengan kajian ini. Sebagai alat bedah permasalahan dalam penelitian ini digunakan teori fenomenologi, teori medis psikoneurohipertensi, dan teori- teori hipertensi. Pembahasan hasil penelitian dilakukan secara deskriptif analitik.

\section{PEMBAHASAN}

\subsection{Umur Kronologis dan Keturunan Memengaruhi Tekanan Darah}

Tabel 3.1

Karakteristik Lansia Berdasarkan Usia

\begin{tabular}{|c|c|c|}
\hline Usia (tahun) & $\mathbf{f}$ & $\%$ \\
\hline $60-70$ & 31 & \\
\hline $71-80$ & 6 & 77,5 \\
\hline $81-90$ & 3 & 15,0 \\
\hline Total & 40 & 7,5 \\
\hline
\end{tabular}

Sumber : data primer 2019

Wawancara dengan lansia dan observasi terhadap kartu tanda pengenal yang dibawanya untuk mengetahui umur, dapat dijelaskan pada tabel 3.1, yaitu ada 40 orang lansia yang mengikuti yoga dan menderita hipertensi. Paling banyak lansia berumur 60-70 tahun yaitu 31 orang $(77,5 \%)$. Dilihat dari umurnya dapat diartikan bahwa kebanyakan dari mereka baru digolongkan lansia sekitar satu sampai sepuluh tahun yang lalu. Dikatakan demikian, karena seseorang dikatakan lansia menurut undangundang nomor 13 tahun 1998 saat mereka berumur 60 tahun. Artinya, bila mereka telah berumur $\geq 60$ tahun barulah disematkan kepadanya sebutan lansia. Lansia yang mengalami suatu pergesaran fungsi di masyarakaat sering mengalami ketidakseimbangan emosi sehingga mudah menjadi cemas (Gerungan, WA. 2004; Hawari Dadang.2008; Suryani, LK. 2010). Pendapat ahli tersebut diperkuat secara empiris subyektif oleh I Made Kad, 61 tahun, pensiunan Aparatur Sipil Negara (ASN), dalam perkatannya ada menyebutkan.

"Saya sebelumnya tidak pernah menderita hipertensi. Semenjak pensiun dari kator gubernur saya jarang mengikuti kegiatan-kegiatan lagi, Ini beruntung di banjar juga ada kelompok lansia yang rutin mengadakan senam dan kegiatan lainnya". (wawancara, 28 Juli, 2019). 
Informan di atas jelas mengatakan sebelumnya ia tidak hipertensi, tetapi setelah pensiun ia menjadi hipertensi. Pensiun secara psikologis memengaruhi kejiwaan seseorang, karena terjadi goncangan psikologis yang berimplikasikepadasistemorgankardiovaskuler untuk terjadinya peningkatan darah. Pada goncangan psikologis terjadi kecemasan atau stres yang akan merangsang dikeluarkannya hormon kortisol (hormon stres) yang memacu jantung untuk berdenyut lebih keras dan pembuluh darah menjadi lebih kecil.

Hal itu sejalan dengan yang dikatakan oleh (Goleman, Daniel. 2015; Wardhana, 2016; Khairani, 2016) bahwa seseorang yang mengalami kegoncangan psikologis akan terjadi rangsangan pada sistem limbik khususnya amigdala sebagai pusat emosi. Amigdala akan merangsang otak bagian hipotalamus untuk bereaksi mengeluarkan hormonnya yang merangsang hipofise anterior mengeluarkan adrenocorticotropin hormon (ACTH). Hormon inilah yang memerintahkan kelenjar anak ginjal mengeluarkan kortisol, adrenalin, dan noradrenalin yang memicu kerja jantung dan mempersempit pembuluh darah (Dee Unglaub Silverthorn. 2013).

Tabel 3.2

Karakteristik Lansia Berdasarkan Riwayat Keluarga Hipertensi

\begin{tabular}{|c|c|c|}
\hline Karakteristik lansia & $f$ & $\%$ \\
\hline Ada hipertensi & 25 & 62.5 \\
\hline Tidak ada hipertensi & 15 & 37,5 \\
\hline Total & 40 & 100,0 \\
\hline
\end{tabular}

Sumber: data primer 2019

Pengumpulan data tentang ada tidaknya keluarga yang menderita hipertensi dilakukan dengan wawancara ditujukan untuk mengetahui faktor keturunan yang memengaruhi hipertensi. Kebanyakan dari lansia yang ikut yoga ada keluarganya menderita hipertensi yaitu 25 orang $(62,5 \%)$. Hipertensi dilihat dari penyebabnya dikelompokkan menjadi dua golongan besar yaitu hipertensi primer dan sekunder. Dikatakan menderita hipertensi primer bila penyebab dari hipertensi tersebut tidak diketahui, sedangkan yang sekunder penyebabnya telah diketahui. Kebanyakan hipertensi yang terjadi di masyarakat penyebabnya tidak diketahui, yaitu hampir 90\%-95\% dari seluruh kejadian hipertensi. Diduga penyebab utamanya adalah faktor keturunan (PERKI,2016; PERHI, 2019). Secara subyektif empiris informan Ni Ketut Sus 64 tahun mengatakan.

"Keluarga memang ada yang hipertensi yaitu adik saya. Kedua orang tua juga mengalami hal yang sama. Saya tahu menderita hipertensi setelah berumur 40 tahun. Saat itu dilakukan pemeriksaan di puskesmas. Tekanan darah saya dibilang tinggi 160/95mmHg. Mulai saat itu saya rajin mengonsumsi obat hipertensi" (Wawancara tanggal 28 Juli 2019)

Dari pengakuan informan di atas dapat dipahami bahwa keluarganya juga ada yang menderita hipertensi, lebih-lebih kedua orang tuanya. Faktor keturunan dan kebiasaan mengkonsumsi garam menjadikan sel-sel tubuh lebih sensitif terhadap garam yang mengakibatkan dikeluarkannya hormon aldosteron sehingga garam makin tertahan di dalam tubuh. Hal tersebut sejalan dengan yang dijelaskan oleh (Dee Unglaub Silverthorn. 2013; Pranawa, Artaria Tjempakasari. 2015) bahwa hipertensi lebih banyak penyebabnya tidak diketahui dan paling banyak dicurigai akibat faktor keturunan.

Dikelompokan menjadi hipertensi sekunder bila penyebabnya telah diketahui dan kebanyakan dari kejadiannya karena penyakitpenyakit pada ginjal. Dapat dimaklumi karena diginjal terjadi penyaringan atau pembersihan darah dari kotoran-kotoran hasil metabolisme di dalam tubuh. Kerusakan yang terjadi pada ginjal mengakibatkan diserapnya kembali garam-garam dan diedarkan ke seluruh tubuh. Dengan demikian, air akan ikut juga diserap yang berakibat meningkatnya volume darah.

Hipertensi merupakan penyakit tidak menular, tetapi pasti menyebabkan kerusakan berlanjut pada organ-organ tubuh, karena dapat merusak pembuluh darah. Kerusakan pada dinding pembuluh memudahkan asam lemak menempel padanya. Asam lemak yang semakin 
banyak akan mempersempit saluran darah sampai menutupnya. Terjadilah kekurangan darah pada organ dihilir dari pembuluh darah tersebut dan menjadi rusak.

Bila yang terkena pembuluh darah di otak terjadilah stroke, diginjal bisa jadi mengakibatkan gagal ginjal kronis, kalau pada mata menjadi retinopati, apalagi yang terkena pembuluh darah jantung bisa mengakibatkan mati jantung atau infark miokard (Sylvia Anderson Price and Lorraine McCarty Wilson. 2008). Beberapa keluarga dari informan ada yang meninggal karena komplikasi dari penyakit hipertensi, seperti yang disampaikan oleh I Nyoman Str, 62 tahun, pensiunan perusahan swasta (Wawancara tanggal 30 Juli 2019) pada beberapa perkataannya ada menyebutkan

"Kakak saya meninggalnya di Rumah Sakit Kapal, sudah tiga tahun yang lalu. Saat itu malam hari sedang menonton TV, kakak mendadak tidak bisa bangun dari kursi karena kaki dan tangan kanannya sulit diangakat. Akhirnya diajak ke Rumah Sakit Kapal. Selama perawatan tekanan darahnya tinggi, sekitar $170 \mathrm{mmHg}$ sampai $180 \mathrm{mmHg}$. Sepuluh hari perawatan keadaannya bertambah buruk akhirnya meninggal. Dokter mengatakan kakak meninggal karena pecahnya pembuluh darah di otak, akibat hipertensi yang dideritanya sejak lama".

Meninggalnya kakak informan di atas karena hipertensi yang kronis. Tekanan darahnya juga selalu di atas $140 \mathrm{mmHg}$. Bila pembuluh darah terus-menerus diterpa dengan tekanan yang tinggi akan menjadi rusak dan memudahkan menempelnya asam-asam lemak padanya. Hipertensi juga terjadi pada kelebihan garam di dalam tubuh. Tidak semua orang yang senang makan garam akan menderita hipertensi, sangat tergantung dari sensitivitas tubuh kepada garam. Makin sensitif makin besar kemungkinan terkena hipertensi. Setiap orang mempunyai sensitivitas yang berbeda terhadap garam. Dengan demikian jumlah asupan garam yang lebih sedikit belum tentu tidak terjadi hipertensi. Garam yang berlebih di dalam tubuh apalagi disertai dengan sensitivitas tubuh yang tinggi terhadapnya mengakibatkan tertahannya air yang berimplikasi kepada meningkatnya volume darah (Dee Unglaub Silverthorn. 2013; Pranawa, Artaria Tjempakasari. 2015)

\subsection{Perbandingan Tekanan Darah Lansia Sebelum dan Setelah Melakukan Yoga Asana.}

Tabel 3.3

Rata-rata TDS dan TDD Sebelum dan Setelah Melakukan Yoga Asana

\begin{tabular}{|l|c|c|c|c|c|}
\hline \multicolumn{1}{|c|}{ Variabel } & N & Min & Max & Mean & SD \\
\hline TDS & & & & & \\
\hline Sebelum yoga & \multirow{2}{*}{40} & 130,0 & 160,0 & 141,0 & 10,3 \\
\cline { 1 - 4 } Setelah yoga & & 100,0 & 140,0 & 120,75 & 10,7 \\
\hline TDD & & & & & \\
\hline Sebelum yoga & \multirow{2}{*}{40} & 70,0 & 100,0 & 90,0 & 8,165 \\
\cline { 1 - 5 } Setelah yoga & & 70,0 & 90,0 & 80,75 & 5,723 \\
\hline
\end{tabular}

Sumber: data primer 2019 setelah diolah

Pengamatan utama tentang TDS dan TDD sebelum dan setelah melakukan yoga asana dapat dijelaskan dari tabel 3 di atas, yaitu sebelum melakukan yoga asana semua lansia yang hipertensi diukur tekanan darahnya. Dari 40 orang lansia tersebut semua tekanan darah sistoliknya (TDS) dijumlahkan dan dibagi dengan 40. Hasilnya, rata-rata tekanan darah lansia adalah $141 \mathrm{mmHg}$. Artinya, secara ratarata tekanan darah lansia berada pada hipertensi, karena yang dimaksud dengan hipertensi sitolik bila tekanan darah $\geq$ $140 \mathrm{mmHg}$. Walaupun ada beberapa lansia yang TDS-nya $130 \mathrm{mmHg}$ dan $160 \mathrm{mmHg}$. Dijelaskan, rata-rata ketinggian TDS lansia tidaklah terlalu tinggi.

Lansia setelah melakukan yoga asana secara teratur tiga kali dalam seminggu yaitu Selasa, Kamis, dan Minggu setiap jam 17.00 selama empat minggu, TDS diukur ulang dan dirataratakan. Ternyata rata-rata TDS-nya menjadi $120,7 \mathrm{mmHg}$, berada dalam batas-batas normal $(<140 \mathrm{mmHg}$ ). Rata-rata TDS setelah melakukan yoga asana turun sebesar $20,25 \mathrm{mmHg}(14,36 \%)$. Penurunan sebesar $14,36 \%$ ini menjadikan ratarata TDS setelah melakukan yoga asana menjadi normal, tidak hipertensi lagi.

Yoga menjelaskan bagaimana manusia dapat mengatasi berbagai bentuk penderitaan yang 
diakibatkan oleh dominannya unsur prakarti yang bersifat rajas dan tamas (Suka Yasa et al.2009). Rajas mempunyai efek pada diri adalah menjadikan manusia agresif. Sedangkan tamas, menjadikan orang bersifat negatif, malas, acuh tak acuh pada lingkungannya. Artinya, mereka yang melakukan yoga asana dapat mengendalikan sifat-sifat tersebut, sehingga menjadi satwam yaitu bersifat riang, cerah, dan senang. Efeknya pada diri adalah menjadikan manusia berkeutamaan.

Dikaitkan dengan sistem kardiovaskuler sifat yang satwan akan mengurangi stres yang berimplikasi terhadap berkurangnya hormon kortisol yang dikeluarkan oleh kelenjar anak ginjal. Suasana yang demikian menjadikan denyut jantung teratur memompa darah dengan kandungan oksigen yang cukup bagi tubuh. Pembuluh darah juga tidak menyempit yang menjadikan tahanan perifer tidak meningkat. Teraturnya denyut jantung dan tidak meningkatnya tahanan perifer merupakan dua faktor yang dapat meniadakan tekanan darah tinggi (Pranawa, Artaria Tjempakasari. 2015). Secara empiris subyektif keluhan-keluhan lansia akibat hipertensi yang dideritanya dirasakan sangat berkurang setelah melakukan yoga asana. Seperti yang diceritakan oleh informan Ni Wayan Mnh, 68 tahun diwawancarai 30 Juli 2019 mengatakan

"Sebelum saya melakukan yoga, sering kepala saya sakit dan terasa berat dileher bagian belakang, bahkan kadang-kadang ada rasa mual. Oleh dokter BPJS tempat saya berobat diberikan penurun tensi. Tetapi, rasa sakit kadang-kadang hilang dan lebih sering kambuhnya. Akhirnya, saya ikut yoga dengan tetap meminum obat dari dokter. Syukurlah, kumatnya sakit kepala berkurang".

Informan seorang wanita diatas menceritakan menderita hipertensi yang diberitahu oleh dokter BPJS di mana dia berobat. Dengan tetap meminum obat antihipertensi sakit kepalanya berkurang tetapi kambuh lagi. Setelah digabungkan pengobatan dari dokter dan melakukan yoga bersama lansia lainnya, sakit kepalanya berkurang dan jarang kambuhnya. Pengakuan senada juga disampaikan oleh I
Nyoman Rn, 69 tahun, yang selalu minum obat antihipertensi dari dokter BPJS yang merawatnya. Pada beberapa pernyataannya ada dikatakan

"Tekanan darah saya memang selalu tinggi, sudah sering berobat ke manamana. Saya bersyukur dengan adanya BPJS, karena saya mendapatkan obat gratis. Sebelumnya saya memakai uang pribadi untuk berobat. Saya ikut mencoba melakukan yoga di banjar berharap dapat menghilangkan tekanan darah tinggi. Memang setelah melakukan yoga saya merasa lebih segar dan tidur menjadi lebih nyenyak" (wawancara 30 Juli 2019).

Informan berusaha semaksimal mungkin untuk mengobati hipertensinya. Mereka juga bersyukur karena tidak lagi banyak mengelurkan biaya untuk berobat. Setelah menggabungkan pengobatan dengan melakukan yoga, perasaannya menjadi lebih segar, sakit kepala berkurang, dan tidur lebih nyenyak. Mereka juga bersyukur karena pengoatannya ditanggung oleh BPJS Kesehatan. Perasaan senang yang mereka rasakan berpengaruh terhadap tekanan darahnya, karena dapat mengurangi bahkan mencegah kontraksi dari pembuluh darah. Efek lainnya denyut jantungpun dibuat teratur. Sejalan dengan hal tersebut Hans Tandra (2019) mengatakan adanya tekanan darah tinggi menekan dan merusak dinding pembuluh darah yang overstretched. Keadaan menjadi lebih berat bila ada pengapuran, penyempitan, hingga pembuntuan pembuluh darah yang bisa berimplikasi menjadi stroke.

Implikasi merupakan keterlibatan atau keadaan terlibat sehingga mempunyai hubungan dengan suatu hal. Implikasi juga diartikan sebagai akibat-akibat dan konsekuensikonsekuensi yang ditimbulkan dengan dilaksanakannya suatu kebijakan atau kegiatan tertentu. Marheni dkk. (2018) mengartikan implikasi sebagai perubahan yang akan terjadi bila sesuatu yang dipahami diaplikasikan dalam kehidupan. Implikasi ini tidak berhenti pada satu akibat, tetapi dapat berantai dari implikasi satu ke implikasi selanjutnya. Akan tetapi, implikasi tidak terjadi begitu saja. Artinya, 
implikasi merupakan proses yang didahului oleh suatu resepsi (penerimaan) tentang sesuatu

Melakukan yoga asana secara diakronis lebih bermanfaat menurunkan tekanan darah daripada sinkronis. Dikatakan demikian, pada sinkronis yoga hanya dilakukan saat-saat tertentu saja, sedangkan secara diakronis dilakukan secara berkelanjutan. Dengan demikian, pengeluaran hormon yang dapat melebarkan pembuluh darah akan terus terjadi dan hormon-hormon stres akan ditekan. Secara empiris obyektif lansia yang melakukan yoga tekanan darahnya akan menurun akibat dari yoga yang dilakukannya.

\subsection{Yoga Asana Menormalkan Tekanan Darah Lansia yang Mengalami Hipertensi}

Tabel 3.4

Pengaruh Yoga Asana Terhadap Tekanan Darah Lansia yang Hipertensi

\begin{tabular}{|l|c|c|c|c|}
\hline \multicolumn{1}{|c|}{ Variabel } & N & $\mathbf{Z}$ & $\begin{array}{c}\text { Beda } \\
\text { rata- } \\
\text { rata }\end{array}$ & $\begin{array}{c}\boldsymbol{P} \\
\text { value }\end{array}$ \\
\hline $\begin{array}{l}\text { TDS } \\
\text { sebelum-setelah yoga }\end{array}$ & \multirow{2}{*}{40} & $-5,579$ & 20,25 & 0,001 \\
\cline { 1 - 4 } $\begin{array}{l}\text { TDD } \\
\text { sebelum-setelah yoga }\end{array}$ & & $-4,770$ & 9,25 & 0,001 \\
\hline
\end{tabular}

Sumber: data primer 2019 setelah diolah

Hasil ketiga yang diperoleh berupa kebermanfaatanyogaasana dalam memengaruhi penurunan tekanan darah lansia hipertensi dapat dijelaskan dari tabel 3.4, yaitu TDS lansia sebelum dan setelah melakukaan yoga asana terjadi penurunan sebesar 20,25mmHg. Dihitung dari sebelum yoga asana TDS menurun sebesar $14,4 \%$ menjadi $120,75 \mathrm{mmHg}$. TDS setelah yoga asana bila dibandingkan dengan standar hipertensi yaitu TDS $\geq 140 \mathrm{mmHg}$, dapat dikatakan setelah melakukan yoga asana ratarata TDS lansia menjadi normal.

TDD juga mengalami penurunan dari $90 \mathrm{mmHg}$ menjadi $80,75 \mathrm{mmHg}$. Penurunan sebesar $0,25 \mathrm{mmHg}$ juga mengantarkan ratarata TDD lansia setelah melakukan yoga asana menjadi normal. Dikatakan demikian, karena seseorang dikatakan hipertensi bila TDD $\geq$
90mmHg. Kedua tekanan darah TDS dan TDD secara empiris obyektif mengalami perubahan yaitu dari kondisi hipertensi menjadi normal.

Pada tabel 3.4 juga dapat dijelaskan, secara statistik adanya beda rata-rata TDS dari sebelum dan setelah yoga asana sebesar $20,25 \mathrm{mmHg}$ adalah bermakna atau signifikan (P $0,001<\alpha$ $0,05)$. Artinya, yoga asana berpenagruh secara bermakna di dalam menurunkan tekanan darah lansia, dari hipertensi menjadi tidak hipertensi. Hal yang sejalan juga terjadi pada TDD beda rata-ratanya sebesar $9,25 \mathrm{mmHg}$ bermakna untuk menurunkan TDD dari hipertensi menjadi normal (P 0,001< $<0,05)$.

Yoga menurut Maharsi Patanjali dalam Yoga Sutra Patanjali, artinya hubungan antara sang aku roh pribadi dengan Sang Sumber pencipta alam semesta. Hubungan yang sejati akan tercapai bila citta 'pikiran' mampu didiamkan atau dikendalikan. Maka Maharsi Patanjali merumuskan yoga sebagai cittawrti nirodah, yaitu usaha untuk mendiamkan 'liarnya' pikiran (Suka Yasa et al.2009). Secara empiris bila dikaitkan dengan menurunnya tekanan darah lansia dari hipertensi menjadi normal setelah melakukan yoga asana dapat dijelaskan, pemusatan pikiran dalam gerakan-gerakan yoga asana bisa mengurangi atau meniadakan kecemasan pada lansia.

Sebagai konsekwensi dari perubahan peran dan fungsinya dimasyarakat lansia memerlukan suatu adaptasi terhadap lingkungannya, yang bisa jadi memunculkan suatu kecemasan. Perubahan peran dan fungsi merupakan stimulus eksternal yang memengaruhi rasa dan pikiran menjadi cemas. Rasa dan pikiran kecemasan merupakan stimulus internal yang berperanan dalam dikeluarkannya hormon pemicu mengecilnya pembuluh darah dan meningkatnya kerja jantung. Yoga berperanan di dalam mendiamkan atau mengendalikan rasa dan pikiran yang 'liar' menjadi terfokus kepada Sang Sumber. Terpusatnya rasa dan pikiran kepada Sang Sumber menjadikan suasana tenang, senang dan gembira. Suasana tersebut menjadikan tubuh relaksasi dan akan menurunkan pengeluaran hormon kecemasan. Sebagai kelanjutananya peningkatan tekanan darahpun dapat dikendalikan.

Temuan secara empiris obyektif dan 
pembuktian dengan statistik di atas dipertegas lagi dengan fakta empiris subyektif seperti yang disampaikan oleh I Wayan Ldr, 65 tahun, penderita hipertensi, pekerjaan pedagang. Pada wawancara yang dilakukan 30 Juli 2019 ada dikatakan

"Sebelum melakukan senam yoga tekanan darah saya terus tinggi kadangkadang mencapai $170 \mathrm{mmHg}$. Tetapi, lebih sering $160 \mathrm{mmHg}$. Saya sudah empat bulan ikut senam di sini setiap minggu dua kali. Sekarang diajak ikut tiga kali. Perasaan setelah yoga menjadi lebih tenang, dan dapat bergaul dengan teman-teman yang juga mempunyai hipertensi. Tekanan darah saya baru diukur tadi hanya $150 \mathrm{mmHg}$ ".

Informan lainnya Ni Ketut Skrt 60 tahun, petani, juga mengatakan hal yang hampir sama.

"Tekanan darah saya sebelum senam yoga berada pada kisaran $150 \mathrm{mmHg}$ $170 \mathrm{mmHg}$. Setelah melakukan yoga menjadi normal $138 \mathrm{mmHg}$. Akan tetapi tekanan darah ini tidak selalu normal kadang-kadang juga lagi naik menjadi $150 \mathrm{mmHg}$. Makanya saya terus ikut senam yoga agar turun tekanan darah saya".

Yoga asana merupkan suatu 'obat' tradisional empiris karena sudah turun-temurun dilakukan. Pada saat ini yoga asana sudah menjadi suatu gaya hidup masyarakat modern, karena diketahui pentingnya dalam menjaga kesehatan. Dengan melakukan olah diri, olah pikiran, dan olah rasa pengendalian terhadap ketiganya tersebut memungkinkan tubuh untuk mengendalikan pengeluaran hormon-hormon kecemasan. Aktifitas sistem kardiovaskuler menjadi lebih ringan dan hipertensipun dapat dikendalikan. Akan tetapi, aktifitas tersebut haruslah dilakukan secara diakronis agar mendapatkan hasil yang optimal.

\section{PENUTUP}

Pengendalian tekanan darah tinggi secara komprehensip dengan obat-obatan konvensional dari dokter dan obat tradisional empiris memberikan hasil yang lebih baik, dibandingkan denga bila digunakan secara terpisah. Yoga asana satu dari sekian banyak gaya hidup yang dapat dipakai sebagai 'obat'tradisional empiris karena secara realitas sudah sering dan banyak digunakan di masyarakat. Gaya hidup ini bisa dikatakan sebagai olahraga dan memengaruhi sistemsistem organ di dalam tubuh. Yoga asana juga menjadikan pikiran dan emosi terkendali sehingga membuat raga menjadi tenang, senang, dan gembira. Saat itulah pengeluaraan hormonhormon stres yang memacu kerja jantung dan pembuluh darah dapat dikendalikan. Dengan demikian, kerja dari jantung lebih optimal dan pembuluh darah menjadi relaksasi, alhasil tekanan darahpun dapat dikendalikan. Agar mendapatkan pengendalian tekanan darah yang optimal perlu minum obata konvensional dari dokter dan melakukan yoga asana. Sebaiknya yoga asana dilakukan secara diakronis karena memberikan hasil penurunan tekanan darah yang lebih baik.

\section{DAFTAR PUSTAKA}

Artadi, I Ketut. 2011. Kebudayaan Spiritualitas: Nilai Makna dan Martabat Kebudayaan: Dimensi Tubuh Akal Roh dan Jiwa. Denpasar: PT Pustaka Bali Post.

Artana, I. W. (2017). Analisis Fungsional Terapi Tradisional dan Terapi Komplementer Alternatif Diera Jaminan Kesehatan Nasional (JKN). Journal Center of Research Publication in Midwifery and Nursing 1 (1).

Dee Unglaub Silverthorn. 2013. Fisiologi Manusia. Sebuah Pendekatan Terintegrasi. Jakarta: EGC Emzir. 2016. Metodologi Penelitian Kualitatif. Analisis Data. Jakarta: Rajawali Press 
Gerungan, WA. 2004. Psikologi Sosial. Bandung: PT Refika Aditama

Goleman, Daniel. 2015. Emotional Intelligence. Jakarta: PT Gramedia Pustaka Utama.

Hans Tandra. 2019. Dari Diabetes Menuju Jantung \& Stroke. Jakarta: PT Gramedia Pustaka Utama

Hawari Dadang. 2008. Manajemen Stres, Cemas, dan Depresi. Jakarta: FK UI

Hemamalini. 2017. "Yoga sebagai Lifestyle Masyarakat Postmodern di Bintaro Jaya" (Disertasi). Denpasar: Program Doktor

Koswara. 2011. Teori-Teori Kepribadian. Psikoanalisis, Behaviorisme, Humanistik. Bandung: PT. Eresco.

Hill, P.C., Hood, R.W., \& Spilka, B. 2009. The Psychology of Religion: An Empirical Approach (4th Ed). New York: Guilford Press.

Kementrian Kesehatan Republik Indonesia. 2014. Hasil Riset Kesehatan Dasar 2013. Jakarta: Kementrian Kesehatan .

Kementrian Kesehatan Republik Indonesia. 2018. Hasil Riset Kesehatan Dasar 2017. Jakarta: Kementrian Kesehatan.

Khairani, Makmun. 2016. Psikologi Umum. Yogyakarta: Aswaja Pressindo.

Marheni, A.A.I.N., Dantes, Nyoman, Astawa I.B.M. 2018. Bahan Ajar Pekerti (Pelatihan Keterampilan Dasar Teknik Instruksional). Jakarta: PT.Raja Grafindo Persada.

Martono, Nanang. 2015. Metode Penelitian Sosial Konsep-Konsep Kunci. Jakarta: PT.Raja Grafindo Persada

Muliadi 2017. Relasi Tuhan dan Manusia (Refleksi Platonis atas Hinduisme). Jurnal Agama dan Lintas Budaya 1, 2 (Maret 2017): 110-122

Nala IGN,2011. Prinsip Pelatihan Fisik Olahraga. Denpasar: Udayana University Press

Nuraeni, Heny Gustini dan Alfan, Muhammad. 2013. Study Budaya Indonesia: Bandung: Pustaka Setia.

Notoatmodjo. 2015. Metodologi Penelitian Kesehatan. Jakarta: Rineka Cipta

PERKI, 2016. Panduan Praktik Klinis (PPK) dan Clinical Pathway (CP) PenyakitJantung dan Pembuluh Darah. Jakarta: Perhimpunan Dokter Spesialis Kardiovaskuler Indonesia

PERHI, 2019. Konsensus Penatalaksanaan Hipertensi 2019. Jakarta: Perhimpunan Dokter Hipertensi Indonesia.

Pranawa, Artaria Tjempakasari. 2015. Hipertensi in Buku Ajar Ilmu Penyakit Dalam.Surabaya: FK UNAIR-RS Soetomo.

Sylvia Anderson Price and Lorraine McCarty Wilson. 2008. Pathophysiology. Clinical Consepts of Disease Processes. Jakarta:EGC

Suka Yasa I Wayan, Wirawan I Gusti Bagus, Prastika I Nyoman. 2008. Roga Versus Yoga. Perspsektif Ayurweda. Denpasar: Unit Kegiatan Yoga Mahasiswa Universitas Hindu Indonesia

Suryani LK. 2010. Meditasi Mencapai Hidup Bahagia. Denpasar: Pustaka Bali Post.

Undang-Undang RI Nomor 13 tahun 1998 Tentang Kesejahteraan lanjut Usia (Lansia)

Wardhana Made. 2016. Pengantar Psikoneuroimunologi. Denpasar: Vaikuntha International Publication.

Widodo GG, Purwanigsih P. 2013. Pengaruh Meditasi Terhadap Kualitas Hidup Lansia Yang Menderita Hipertensi Di Unit Rehabilitasi Sosial Wening Wardoyo Ungaran Kabupaten Semarang. J Keperawatan Med Bedah. 2013;1(2):111-8. 